\title{
Intracholecystic papillary neoplasm of the gallbladder diagnosed during follow-up of Menetrier's disease: A case report
}

\author{
SHINGO SHIMADA ${ }^{1}$, TOMOKI HOMMA ${ }^{1}$, KANAME KOYANAGI $^{1}$, KAZUYA HAMADA ${ }^{1}$, \\ CHISAKO MIURA $^{2}$, ICHIRO MIURA ${ }^{2}$ and HIRONORI ABE ${ }^{1}$ \\ Departments of ${ }^{1}$ Surgery and ${ }^{2}$ Pathology, Hokkaido Social Work Association \\ Obihiro Hospital, Obihiro, Hokkaido 080-0805, Japan
}

Received April 27, 2021; Accepted September 6, 2021

DOI: $10.3892 /$ mco.2021.2396

\begin{abstract}
Intracholecystic papillary neoplasm of the gallbladder (ICPN) is a type of intraductal papillary neoplasm of the bile duct that occurs in the gallbladder, and is a relatively newer concept. Therefore, there are few reports regarding ICPN. Menetrier's disease is a rare disease characterized by giant hypertrophy of the gastric folds that causes protein-losing gastroenteropathy (PLG). Although Menetrier's disease is a known risk factor for gastric adenocarcinoma, the association between Menetrier's disease and malignancy other than a malignancy of the stomach is unclear. A 69-year-old man presented to the Hokkaido Social Work Association Obihiro Hospital with gallbladder tumours diagnosed by ultrasonography at a previous institution. In addition, he had previously been diagnosed with PLG due to Menetrier's disease. Abdominal contrast-enhanced computed tomography (CT) revealed an irregular mass with a contrast effect at the fundus of the gallbladder on the free abdominal cavity side. Positron emission tomography-CT showed a tumour with a standard uptake value (SUV) of 8.28 at the fundus of the gallbladder. Cholecystectomy and resection of the gallbladder bed were performed. Based on the microscopy findings, the patient was diagnosed with ICPN. Although he had postoperative ileus, he was discharged 14 days postoperatively due to improvement through conservative treatment. Such cases
\end{abstract}

Correspondence to: Dr Shingo Shimada, Department of Surgery, Hokkaido Social Work Association Obihiro Hospital, East 5-South 9-2, Obihiro, Hokkaido 080-0805, Japan

E-mail: shingoshimada1979@true.ocn.ne.jp

Abbreviations: BilIN, biliary intraepithelial neoplasia; IPNB, intraductal papillary neoplasm of the bile duct; ICPN, intracholecystic papillary neoplasm of the gallbladder; PLG, protein-losing gastroenteropathy; H. pylori, Helicobacter pylori; CT, computed tomography; MRCP, magnetic resonance cholangiopancreatography; SUV, standard uptake value; TGF- $\alpha$, transforming growth factor $\alpha$; EGFR, epidermal growth factor receptor

Key words: ICPN, gallbladder cancer, resection, Menetrier's disease, IPNB of ICPN complicated with Menetrier's disease are extremely rare. However, patients with Menetrier's disease may need to be screened for malignancies.

\section{Introduction}

Precancerous lesions of the bile duct system were classified by the WHO in 2010 as biliary intraepithelial neoplasia (BilIN) and intraductal papillary neoplasm of the bile duct (IPNB) (1). Intracholecystic papillary neoplasm of the gallbladder (ICPN) is a type of IPNB that occurs at the gallbladder (2). Adsay et al (3) reported that ICPN shows the following characteristics: Intramucosal, preinvasive neoplastic or dysplastic mass formation that is exophytic (papillary or polypoid), $\geq 1.0 \mathrm{~cm}$ in size, and compact and distinct from the neighbouring mucosa (3). This concept is relatively new, and therefore, there are few reports regarding ICPN.

Menetrier's disease was first reported as a disease, which showed extensive gastric mucosal proliferation with hypoproteinaemia in 1888 by Menetrier (4). Menetrier's disease is a rare disease characterized by giant hypertrophy of the gastric folds that cause protein-losing gastroenteropathy (PLG) $(5,6)$. Patients with Menetrier's disease often show symptoms such as diarrhoea, abdominal pain, nausea, postprandial fullness and weight loss $(7,8)$. Menetrier's disease is also known as a possible risk factor for gastric cancer, with the incidence of gastric cancer reaching $10 \%$ in patients with Menetrier's disease (7). Although Menetrier's disease is associated with malignancy, few malignancies other than that of the stomach has been reported $(9,10)$, the relationship between Menetrier's disease and malignancies other than those of the stomach are unclear. Herein, a case of a resected ICPN complicated with Menetrier's disease that showed PLG is described.

\section{Case report}

A 69-year-old man presented to Hokkaido Social Work Association Obihiro Hospital with gallbladder tumours diagnosed by ultrasonography at a previous hospital. He was diagnosed with PLG due to Menetrier's disease at a previous hospital 2 years ago, and had visited the previous hospital to receive intravenous albumin every week. In addition, gallbladder tumours were incidentally found during the 
follow-up for Menetrier's disease. The patient had no history of abdominal surgery. Regarding Menetrier's disease, fundic gland hyperplasia was found in biopsies from the gastric mucosa. Helicobacter pylori (H. pylori) analysis came back negative. There were no abnormalities in the results of the colonoscopy or capsule endoscopy of the small intestine. He suffered from diarrhoea, and exhibited iron deficiency $(15 \mu \mathrm{g} / \mathrm{dl})$ and hypoalbuminemia $(2.6 \mathrm{~g} / \mathrm{dl})$ at diagnosis of Menetrier's disease. His body weight was $52.9 \mathrm{~kg}$ at diagnosis of Menetrier's disease.

Ultrasonography showed a cauliflower homogenous tumour that was $2.7 \mathrm{~cm}$ in maximum diameter with a blood supply at the fundus of the gallbladder (Fig. 1). Abdominal contrast-enhanced computed tomography (CT) showed an irregular mass with a contrast effect at the fundus of the gallbladder on the free abdominal cavity side. Abdominal CT also revealed an oedematous and dilated small intestine (Fig. 2). Magnetic resonance cholangiopancreatography (MRCP) showed an intracholecystic papillary torose lesion at the fundus and a dilated common bile duct with a paraduodenal diverticulum. MRCP also revealed pancreatic divisum with a dilated Santorini duct and indistinct Wirsung duct (Fig. 3). Positron emission tomography-CT showed a tumour with a SUV of 8.28 at the fundus of the gallbladder (Fig. 4). Serum levels of carcinoembryonic antigen, carbohydrate antigen 19-9 and carbohydrate antigen 125 were within the normal ranges $(2.1 \mathrm{mg} / \mathrm{ml},<2.0 \mathrm{U} / \mathrm{ml}$ and $8.5 \mathrm{U} / \mathrm{ml}$, respectively). Moreover, low serum albumin (serum albumin, $3.1 \mathrm{~g} / \mathrm{dl}$ ) and anaemia (haemoglobin, $8.4 \mathrm{~g} / \mathrm{dl}$ ) were observed (Table I). Serum iron was $14 \mu \mathrm{g} / \mathrm{dl}$. Body weight was $47.6 \mathrm{~kg}$. Gastroscopy showed swelling, and thick gastric folds were observed in the greater curvature of the body of the stomach (Fig. 5).

A diagnosis of gallbladder tumours was reached, but it was not possible to rule out gallbladder cancer preoperatively. Therefore, a cholecystectomy with resection of the gallbladder bed by laparotomy was planned; thereafter, an intraoperative frozen section for gallbladder tumours to judge whether to perform lymph node dissection was planned.

During laparotomy, the tumour was located at the fundus of the gallbladder on the free abdominal cavity side. The serosa of the gallbladder was smooth. No hepatic invasion or peritoneal dissemination was found. Cholecystectomy and resection of the gallbladder bed were performed. Based on the assessment of the intraoperative frozen section, the tumour was diagnosed as adenocarcinoma in adenoma, which was categorized as carcinoma in situ. Therefore, a lymph node dissection was not performed.

Macroscopic findings of the resected specimen are shown in Fig. 6. The tumour, visible as a small, fused grain that was $2.7 \times 2.0 \mathrm{~cm}$, was located at the fundus of the gallbladder. Microscopic examination revealed that most of the tumour showed BilIN 2-3, which preserved polarity. Based on these findings, it was diagnosed as carcinoma in situ (Fig. 7). No vascular invasion or nerve invasion was found. Immunohistochemical staining yielded the following results: p16 was $1 \%$, S100P was negative, the E3 ubiquitin-protein ligase MIB1 index was $80 \%$ (Fig. 8A), the p53 index was $20 \%$ (Fig. 8B) and epidermal growth factor receptor (EGFR) was negative (Fig. 8C). The tumour was classed as ICPN, and mild chronic inflammation was found at the gallbladder.
Table I. Laboratory data.

\begin{tabular}{|c|c|}
\hline Data & Value \\
\hline \multicolumn{2}{|l|}{ Blood counts } \\
\hline White blood cell & $7,060 \mu 1$ \\
\hline Red blood cell & $3.53 \times 10^{6} / \mu 1$ \\
\hline Haemoglobin & $8.4 \mathrm{~g} / \mathrm{dl}$ \\
\hline Haematocrit & $28.9 \%$ \\
\hline Platelet & $43.8 \times 10^{4}$ \\
\hline \multicolumn{2}{|l|}{ Clotting parameter } \\
\hline Prothrombin time & $13.1 \mathrm{sec}$ \\
\hline Activated partial prothrombin time & $28 \mathrm{sec}$ \\
\hline \multicolumn{2}{|l|}{ Biochemical parameters } \\
\hline $\mathrm{Na}^{+}$ & $139 \mathrm{mmol} / \mathrm{l}$ \\
\hline $\mathrm{K}^{+}$ & $4.4 \mathrm{mmol} / \mathrm{l}$ \\
\hline $\mathrm{Cl}^{-}$ & $107 \mathrm{mmol} / \mathrm{l}$ \\
\hline $\mathrm{Ca}^{+}$ & $7.8 \mathrm{mg} / \mathrm{dl}$ \\
\hline Total protein & $6.2 \mathrm{~g} / \mathrm{dl}$ \\
\hline Albumin & $3.1 \mathrm{~g} / \mathrm{dl}$ \\
\hline Total bilirubin & $0.1 \mathrm{mg} / \mathrm{dl}$ \\
\hline Aspartate aminotransferase & $32 \mathrm{U} / \mathrm{I}$ \\
\hline Alanine aminotransferase & $25 \mathrm{U} / \mathrm{I}$ \\
\hline Alkaline phosphatase & $567 \mathrm{U} / \mathrm{I}$ \\
\hline$\gamma$-glutamyltransferase & $10 \mathrm{U} / \mathrm{I}$ \\
\hline Amylase & $158 \mathrm{U} / \mathrm{I}$ \\
\hline Blood urea nitrogen & $19.5 \mathrm{mg} / \mathrm{dl}$ \\
\hline Creatinine & $0.46 \mathrm{mg} / \mathrm{dl}$ \\
\hline C-reactive protein & $0.15 \mathrm{mg} / \mathrm{dl}$ \\
\hline \multicolumn{2}{|l|}{ Tumour marker } \\
\hline Carcinoembryonic antigen & $2.1 \mathrm{ng} / \mathrm{dl}$ \\
\hline Carbohydrate antigen 19-9 & $<2.0 \mathrm{U} / \mathrm{ml}$ \\
\hline Carbohydrate antigen 125 & $8.5 \mathrm{U} / \mathrm{ml}$ \\
\hline
\end{tabular}

Although the patient developed paralytic ileus, he was discharged on postoperative day 14 because of improvement via conservative treatment, and he has been followed up without tumour recurrence for 12 months. However, there was no improvement or worsening of PLG. Body weight was $48.0 \mathrm{~kg}$. Although serum albumin was $2.6 \mathrm{~g} / \mathrm{dl}$, he did not receive intravenous albumin after surgery.

This case report was approved by the institutional review board at the Hokkaido Social Work Association Obihiro Hospital (2020-17). Informed consent was obtained from the patient for the publication of his clinical data and images.

\section{Discussion}

IPNB in the bile duct epithelium is the counterpart of intraductal papillary mucinous neoplasm in the pancreatic duct epithelium $(11,12)$. Similarly, the corresponding gallbladder lesion is defined as ICPN (2). Detailed reports of ICPN are limited, due to the relatively recent classification of this condition. Argon et al (13) reported that the frequency of ICPN was 45 out of 7,334 cholecystectomies, or $0.6 \%$. ICPN 


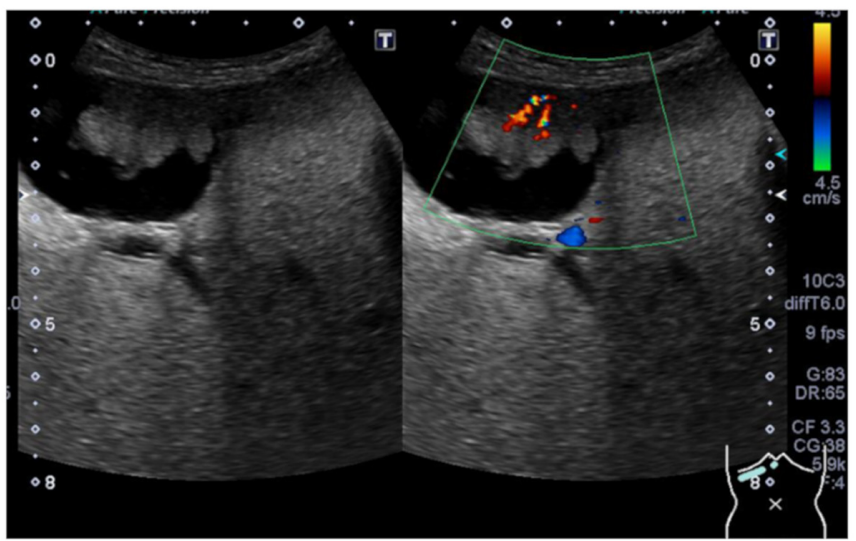

Figure 1. Ultrasonography revealed a cauliflower-like homogenous tumour, which was $2.7 \mathrm{~cm}$ at its maximum diameter, at the fundus of the gallbladder, and colour Doppler imaging showed the blood supply to the tumour.

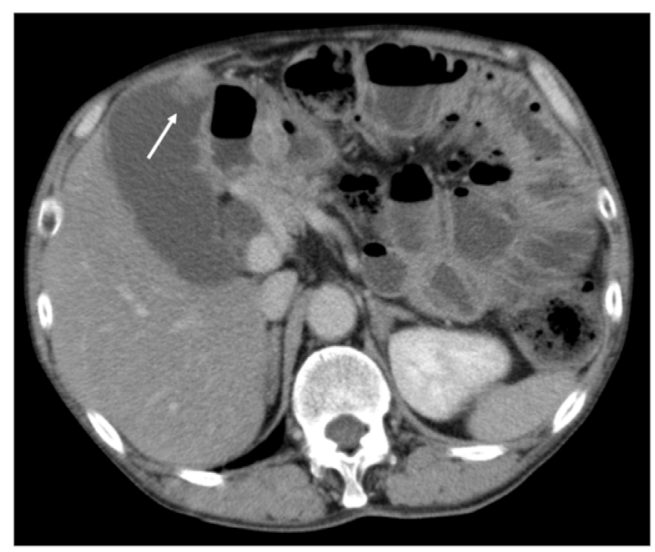

Figure 2. Abdominal contrast-enhanced computed tomography showed an irregular mass with a contrast effect at the fundus of the gallbladder (white arrow) and an oedematous and dilated small intestine.

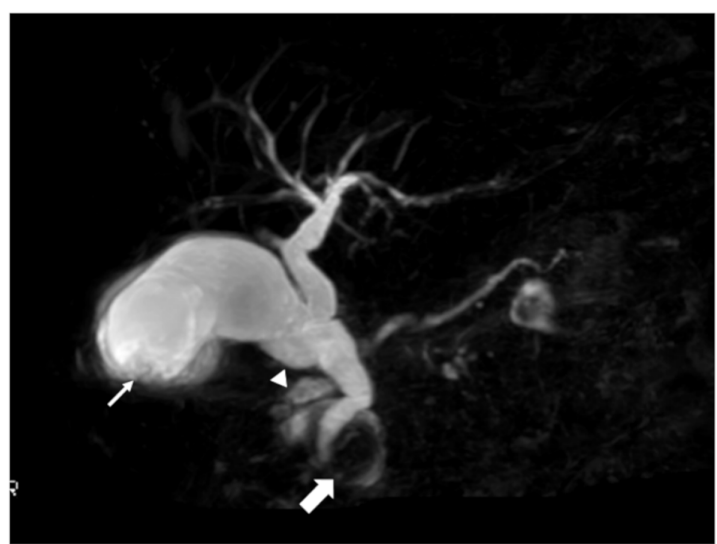

Figure 3. Magnetic resonance cholangiopancreatography showed an intracholecystic papillary torose lesion at the fundus (white arrow), a dilated Santorini duct (white arrowhead), an indistinct Wirsung duct and a dilated common bile duct with a paraduodenal diverticulum (white bold arrow).

with invasive carcinoma components accounts for approximately $55 \%$ of cases, and the proportion of cases of cholelithiasis accompanying ICPNs has been found to be $20-22 \%(3,13)$. In general, few cases of ICPN diagnosed preoperatively, such as

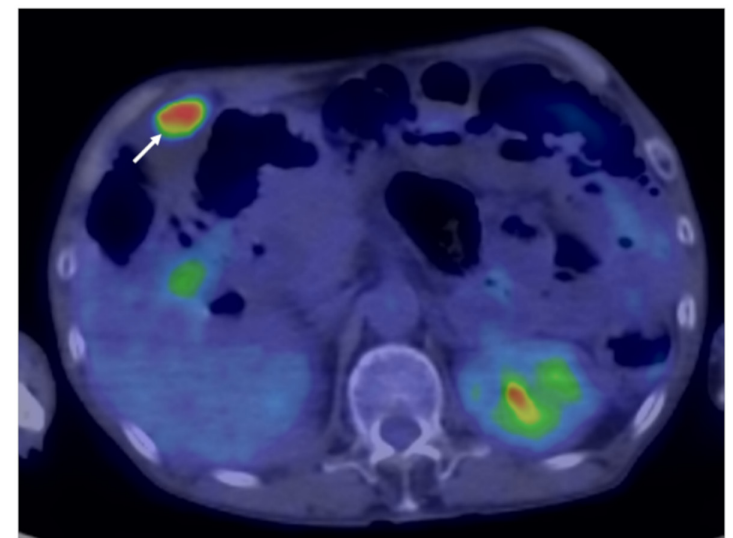

Figure 4. Positron emission tomography-computed tomography showed a tumour with a standard uptake value of 8.28 at the fundus of the gallbladder (white arrow).

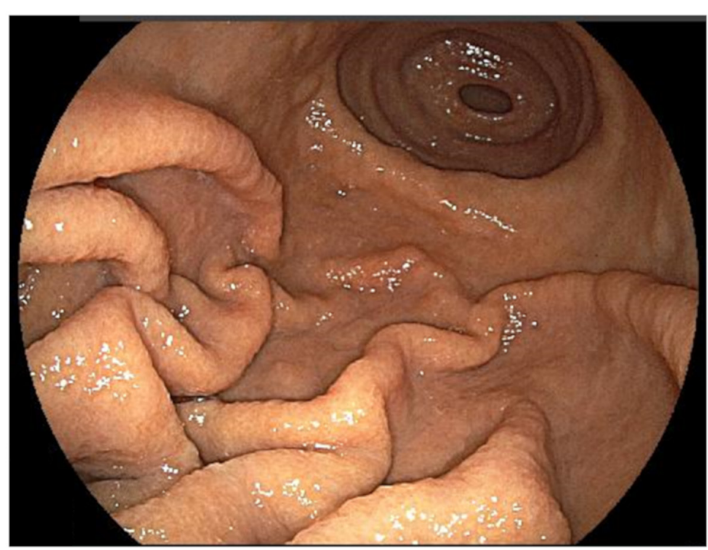

Figure 5. Gastroscopy showed swelling, and thick gastric folds were observed in the greater curvature of the body of the stomach.

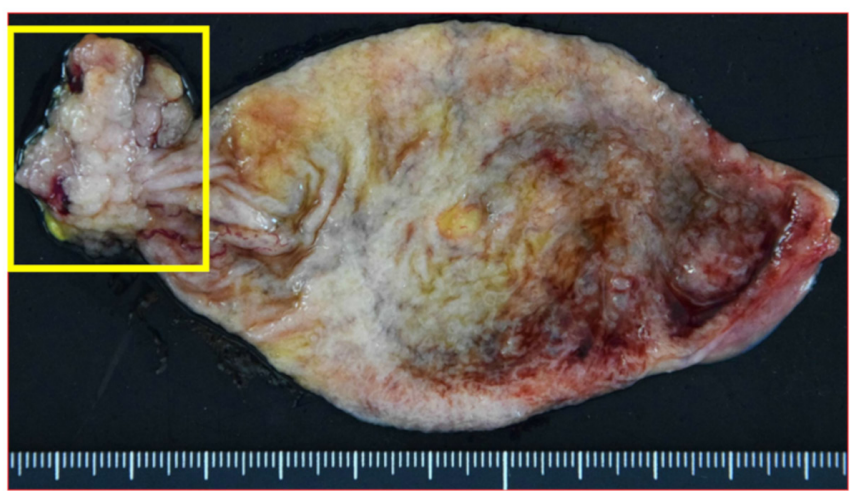

Figure 6. Macroscopic figure before frozen section preparation: Micropapillary tumour, $30 \times 22 \times 12 \mathrm{~mm}$ in size, at the base of the gallbladder (yellow rectangular frame).

the present case, have been reported (14). Previous case reports used imaging modalities to show papillary or papillonodular tumours within the gallbladder $(14,15)$. However, it is very difficult to diagnose ICPN with carcinoma preoperatively.

Recently, Kang et al (16) compared ICPN to conventional adenocarcinoma of the gallbladder. According to their report, 

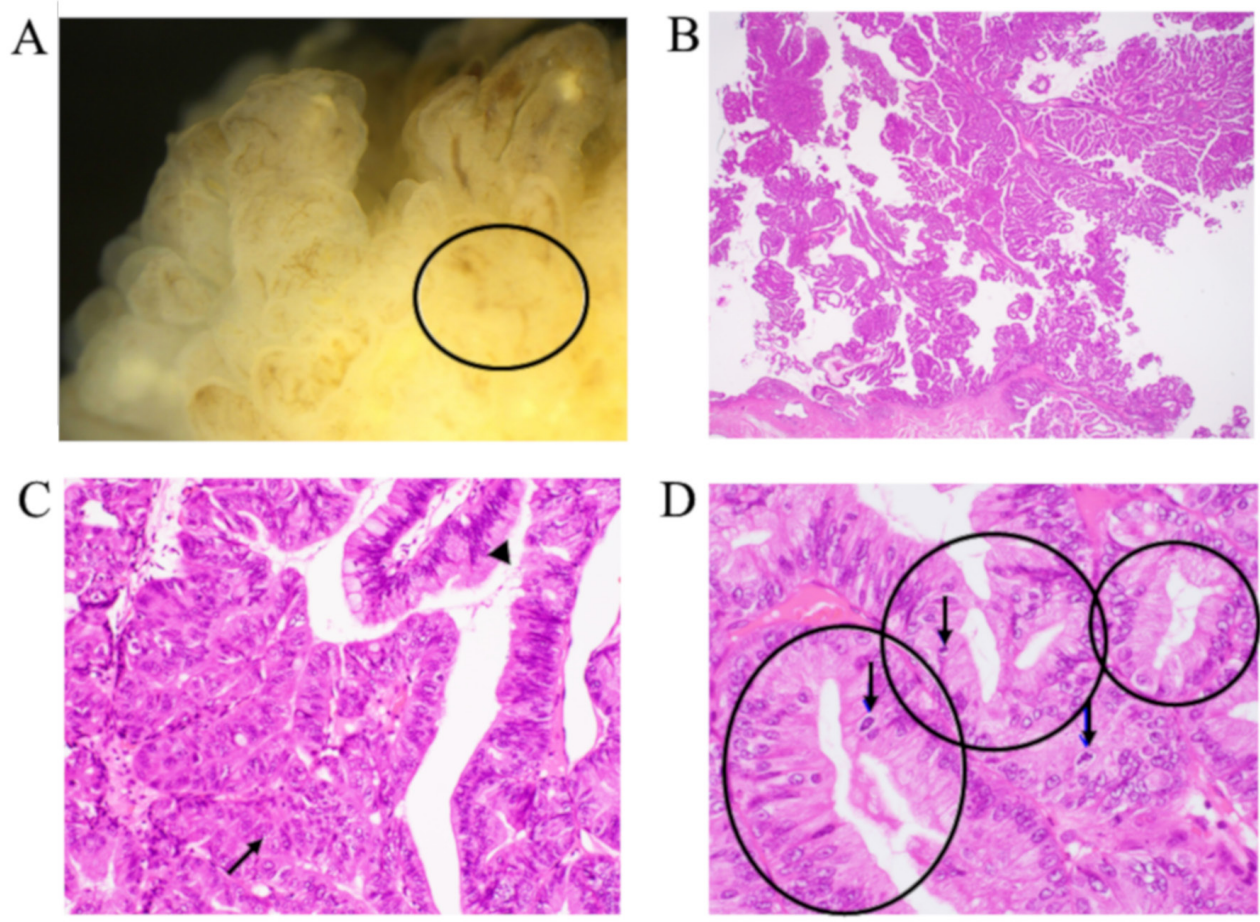

Figure 7. Stereomicroscopic and microscopic images of haematoxylin eosin staining. (A) Stereomicroscopic image in a water-soaked state: Yellow-white tumour consisting of an overlapping flat lesion with reticular capillary proliferation. Within the black circle, the thick pale yellow solid part inside is a cancer. (B) Microscopic image at $\mathrm{x} 4$ magnification. Papillary proliferation of tumour cells with an interstitium including the vessels. (C) Microscopic image at x20 magnification: Left, adenocarcinoma with structural irregularities and mitosis (black arrow). Right upper; villous adenoma containing goblet cells (black arrowhead). (D) Microscopic image at x40 magnification: Proliferation of cells consisting of large nuclei with prominent nucleoli and scattered mitosis. Within the black circles, cancer consisting of proliferated goblet cells. Black arrows: mitotic figures.
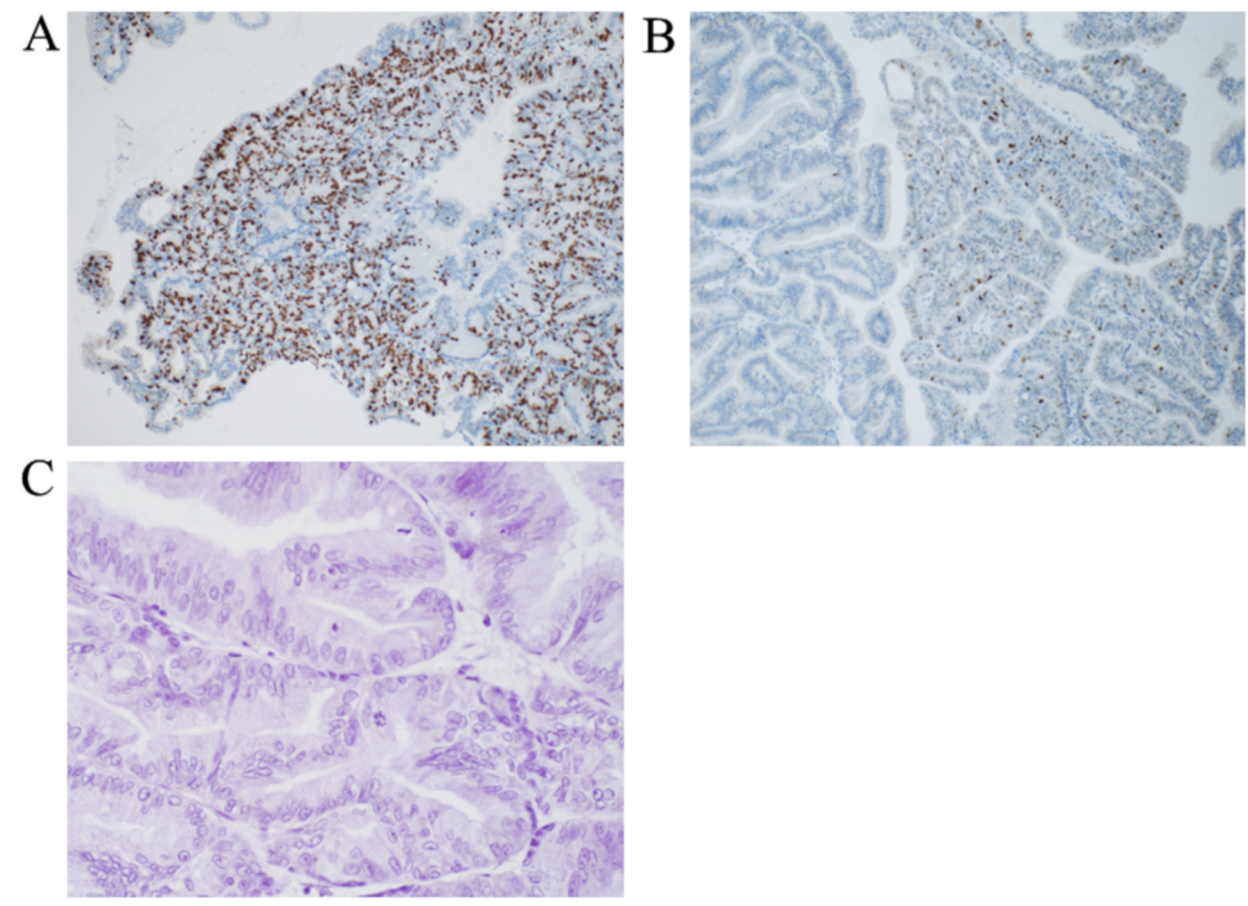

Figure 8. Immunohistochemical staining images. (A) MIB-1 staining: The majority of tumour cells in the region with strong structural atypia showed MIB-1 positive staining of the nuclei. (B) p53 staining: Right, p53-positive cells were found in the region with strong structural atypia. Left, few p53-positive cells were found. (C) EGFR staining: Few EGFR-positive cells were found in the region with strong structural atypia. MIB-1, E3 ubiquitin-protein ligase MIB1; EGFR, epidermal growth factor receptor.

patients with ICPN seemed to exhibit a greater macro- and microscopic curative resection rate, lower preoperative serum carcinoembryonic antigen and carbohydrate antigen 19-9 levels, improved differentiation grade, lower regional lymph 
node metastasis rates and lower rates of distant metastases. In addition, Adsay et al (3) reported that ICPN tended to be detected at an earlier stage than conventional gallbladder carcinoma, and they showed that the proportion of patients with T1 ICPN and that of patients with conventional gallbladder carcinoma were 32 and 9\%, respectively. In the present case, T0 stage and both carcinoembryonic antigen and carbohydrate antigen 19-9 were within the normal ranges, with no metastases. Although reports regarding the prognoses of ICPN are limited, the 5-year OS rate of ICPN has been investigated and found to be $63-73 \%(15,16)$. The proportion of patients without invasive carcinoma is reported to be $71-78 \%$, and $60-61 \%$ of such patients have invasive carcinoma $(3,13)$. Conventional gallbladder cancer exhibits 5-year OS rates of 26-43\% $(16,17)$. In a previous study, ICPN seemed to yield a better prognosis than conventional gallbladder cancer, but the prognoses and local and systemic recurrence rates were similar after T-stage matching (16). Therefore, patients with advanced ICPN should receive adjuvant systemic chemotherapy. In this case, a cholecystectomy with resection of the gallbladder bed was performed, and the tumour was diagnosed as adenocarcinoma in adenoma, which was categorized as carcinoma in situ based on intraoperative frozen sections. Therefore, a lymph node dissection or perform adjuvant therapy were not performed.

While Menetrier's disease is known as a rare disease characterized by giant hypertrophy of the gastric folds that causes PLG $(5,6)$, to date, no definite diagnostic criteria have been established. Although the exact mechanism of the development of Menetrier's disease is not yet clear, it has been hypothesized that this disease is associated with overexpression of transforming growth factor- $\alpha(\mathrm{TGF}-\alpha)$ in the gastric mucosa, resulting in gastric wall thickening and the suppression of gastric acid $(18,19)$. TGF- $\alpha$ combines with EGFR and plays a role in cell proliferation. These mechanisms are similar to those underlying the development of malignant tumours. TGF- $\alpha$ and EGFR facilitate cell proliferation, invasion, metastases and angiogenesis in malignant tumours $(20,21)$. The cause of activation or overexpression of TGF- $\alpha$ and EGFR in Menetrier's disease is unclear; it has been proposed that $H$. pylori in adults and cytomegalovirus in children are related to this activation or overexpression $(22,23)$. While patients with Menetrier's disease are a population that are at high risk for gastric malignancy (7), the possible correlation between Menetrier's disease and a malignancy other than a malignancy of the stomach is still unknown. Sato et al (24) reported a case of Menetrier's disease seemingly caused by hilar cholangiocarcinoma (24). Analysis of their case showed that H.pylori was negative, and PLG significantly improved after resection of hilar cholangiocarcinoma. In addition, cancer cells were positive for both TGF- $\alpha$ and EGFR. In the present case, although $H$. pylori was negative, the cause of Menetrier's disease was not considered due to ICPN, as the discovery of ICPN was 2 years after the onset of Menetrier's disease. Additionally, tumour cells were negative for EGFR, and the patient did not show significant improvement in PLG after surgery. The present case may represent a pure coincidence of Menetrier's disease and IPCN, both of which are rare diseases. However, it has been reported that the rate of EGFR expression is significantly lower in early cancer than in advanced cancer (25). Because the present case presented with carcinoma in situ, the stage may have been too early for the expression of
EGFR to be detectable. Therefore, it was not possible to rule out a carcinogenesis related to the Menetrier's disease. Data on additional cases of Menetrier's disease combined with malignancy not involving the stomach are thus required.

Regarding postsurgical complications, evidence is lacking as to whether patients with Menetrier's disease have a higher risk or incidence of postsurgical complications. Furthermore, certain patients with PLG show postoperative complications after surgery due to low protein levels and nutritional status. In addition, certain patients with PLG present ileus $(26,27)$ or non-occlusive mesenteric ischemia (28). The patient in the present case showed ileus after cholecystectomy and improvement after conservative treatment. Therefore, it may be necessary to monitor for the onset of ileus after surgery in patients with PLG.

Limitations of the present study to be acknowledged are: Protein content in the bile sample was not evaluated; this should be taken into consideration to monitor protein loss. Additionally, TGF- $\alpha$ staining of the resected specimen could not be performed due to a lack of available facilities to perform such experiments.

In conclusion, a case of resected ICPN complicated with Menetrier's disease in a patient who showed PLG is described in the present report. Such cases are extremely rare, however, patients with Menetrier's disease may need to be screened for malignancies.

\section{Acknowledgements}

Not applicable.

\section{Funding}

No funding was received.

\section{Availability of data and materials}

All data generated or analysed during this study are included in this published article.

\section{Authors' contributions}

SS wrote the manuscript. SS, TH and KH performed the surgical procedure. KK and HA managed the perioperative course. IM and $\mathrm{CM}$ performed the pathological diagnosis. All authors have read and approved the final version of the manuscript. SS, TH, and $\mathrm{KH}$ confirm the authenticity of all the raw data.

\section{Ethics approval and consent to participate}

This case report was approved by the institutional review board at the Hokkaido Social Work Association Obihiro Hospital (2020-17).

\section{Patient consent for publication}

Informed consent was obtained from the patient for the publication of his clinical data and images.

\section{Competing interests}

The authors declare that they have no competing interests. 


\section{References}

1. Nakanuma Y, Curabo MP, Franceschi S, Gores G, Paradis V, Sripa B, Tsui WMS and Wee A: Intrahepatic cholangiocarcinoma. In: WHO Classification of Tumours of the Digestive System. Bosman FT, Carneiro F, Hruban RH and Theise ND (eds). 4th edition. IARC Press, Lyon, pp217-p224, 2010.

2. Albores-Saavedra J, Adsay NV, Crawford JM, Klimstra DS, Klöppel G, Sripa B, Tsui WMS and Paradis V: Carcinoma of the gallbladder and extrahepatic bile ducts. WHO Classification of Tumours of the Digestive System: World Health Organization of Tumours. Bosman FT, Carneiro F, Hruban RH and Theise ND (eds). 4th edition. IARC Press, Lyon, pp266-p273, 2010.

3. Adsay V, Jang KT, Roa JC, Dursun N, Ohike N, Bagci P, Basturk O, Bandyopadhyay S, Cheng JD, Sarmiento JM, et al: Intracholecystic papillary-tubular neoplasms (ICPN) of the gallbladder (neoplastic polyps, adenomas, and papillary neoplasms that are $\geq 1.0 \mathrm{~cm}$ ): Clinicopathologic and immunohistochemical analysis of 123 cases. Am J Surg Pathol 36: 1279-1301, 2012.

4. Menetrier P: Des polyadenomes gastriques et deleurs rapports avec le cancer de l'estomac. Arch Physiol Norm Pathol 1: 32-55; 236-262, 1888.

5. Jarnum S and Jensen KB: Plasma protein turnover (albumin, transferrin, $\operatorname{IgG}, \operatorname{IgM}$ ) in Ménétrier's disease (giant hypertrophic gastritis): Evidence of non-selective protein loss. Gut 13: 128-137, 1972.

6. Wolfsen HC, Carpenter HA and Talley NJ: Menetrier's disease: A form of hypertrophic gastropathy or gastritis? Gastroenterology 104: 1310-1319, 1993.

7. Almazar AE, Penfield JD, Saito YA and Talley NJ: Survival times of patients with Menetrier's disease and risk of gastric cancer. Clin Gastroenterol Hepatol 19: 707-712, 2021.

8. Kamal MU, Tariq H, Mehak V, Azam S, Kumar K, Niazi M and Dev A: A rare etiology of abnormally large gastric folds: Menetrier's disease. Case Rep Gastrointest Med 2019: 7927083, 2019.

9. Pryczynicz A, Bandurski R, Guzińska-Ustymowicz K, Niewiarowska K, Kemona A and Kędra B: Ménétrier's disease, a premalignant condition, with coexisting advanced gastric cancer: A case report and review of the literature. Oncol Lett 8: 441-445, 2014.

10. Kuo AH, Martinez N and Rosenkranz L: A concurrent case of Menetrier's disease and signet ring carcinoma. ACG Case Rep J 3: e176, 2016.

11. Zen Y, Sasaki M, Fujii T, Chen TC, Chen MF, Yeh TS, Jan YY, Huang SF, Nimura Y and Nakanuma Y: Different expression patterns of mucin core proteins and cytokeratins during intrahepatic cholangiocarcinogenesis from biliary intraepithelial neoplasia and intraductal papillary neoplasm of the bile duct an immunohistochemical study of 110 cases of hepatolithiasis. J Hepatol 44: 350-358, 2006.

12. Rocha FG,Lee H,Katabi N, DeMatteo RP,Fong Y,D'Angelica MI, Allen PJ, Klimstra DS and Jarnagin WR: Intraductal papillary neoplasm of the bile duct: A biliary equivalent to intraductal papillary mucinous neoplasm of the pancreas? Hepatology 56: 1352-1360, 2012.

13. Argon A, Barbet FY and Nart D: The relationship between intracholecystic papillary-tubular neoplasms and invasive carcinoma of the gallbladder. Int J Surg Pathol 24: 504-511, 2016.

14. Hara A, Kamata K, Takenaka M, Chikugo T and Kudo M: Intracystic papillary neoplasm preoperatively diagnosed by high-quality cytology derived from endoscopic nasogallbladder drainage. Gastrointest Endosc 89: 1257-1259, 2019.
15. Akita M, Fujikura K, Ajiki T, Fukumoto T, Otani K, Hirose T, Tominaga $M$, Itoh $\mathrm{T}$ and Zen $\mathrm{Y}$ : Intracholecystic papillary neoplasms are distinct from papillary gallbladder cancers: A clinicopathologic and exome-sequencing study. Am J Surg Pathol 43: 783-791, 2019.

16. Kang JS, Lee KB, Choi YJ, Byun Y, Han Y, Kim H, Kwon W, Jang JY: A comparison of outcomes in patients with intracholecystic papillary neoplasms or conventional adenocarcinomas of the gallbladder. Available from: https://doi. org/10.1016/j.hpb.2020.09.011.

17. Creasy JM, Goldman DA, Gonen M, Dudeja V, O'Reilly EM, Abou-Alfa GK, Cercek A, Harding JJ, Balachandran VP, Drebin JA, et al: Evolution of surgical management of gallbladder carcinoma and impact on outcome: Results from two decades at a single-institution. HPB (Oxford) 21: 1541-1551, 2019.

18. Dempsey PJ, Goldenring JR, Soroka CJ, Modlin IM, McClure RW, Lind CD, Ahlquist DA, Pittelkow MR, Lee DC, Sandgren EP, et al: Possible role of transforming growth factor alpha in the pathogenesis of Ménétrier's disease: Supportive evidence form humans and transgenic mice. Gastroenterology 103: 1950-1963, 1992.

19. Nomura S, Settle SH, Leys CM, Means AL, Peek RM Jr, Leach SD, Wright CV, Coffey RJ and Goldenring JR: Evidence for repatterning of the gastric fundic epithelium associated with Ménétrier's disease and TGFalpha overexpression. Gastroenterology 128: 1292-1305, 2005.

20. Kidd M, Schimmack S, Lawrence B, Alaimo D and Modlin IM: EGFR/TGFalpha and TGFbeta/CTGF signaling in neuroendocrine neoplasia: Theoretical therapeutic targets. Neuroendocrinology 97: 35-44, 2013.

21. Ciardiello F and Tortora G: Epidermal growth factor receptor (EGFR) as a target in cancer therapy: Understanding the role of receptor expression and other molecular determinants that could influence the response to anti-EGFR drugs. Eur J Cancer 39: 1348-1354, 2003.

22. Badov D, Lambert JR, Finlay M and Balazs ND: Helicobacter pylori as a pathogenic factor in Ménétrier's disease. Am J Gastroenterol 93: 1976-1979, 1998.

23. Megged O and Schlesinger Y: Cytomegalovirus-associated protein-losing gastropathy in childhood. Eur J Pediatr 167: 1217-1220, 2008 .

24. Sato N, Nakahara K, Morita R, Suetani K, Michikawa Y, Nakano H, Koizumi S, Otsubo T, Fujino T and Itoh F: A case of Ménétrier's disease seemingly caused by hilar cholangiocarcinoma. Nihon Shokakibyo Gakkai Zasshi 113: 975-982, 2016.

25. Takemura K, Obara T, Okano S, Yokota K, Ura H, Saitoh Y, Koike Y, Okamura K and Namiki M: Immunohistochemical study on the expression of epidermal growth factor receptor (EGFR) in human colorectal carcinomas. Nihon Shokakibyo Gakkai Zasshi 88: 1177-1183, 1991.

26. Schaad U, Zimmermann A, Gaze H, Kaiser G, Vésy J and Hadorn B: Protein-losing enteropathy due to segmental erosive and ulcerative intestinal disease cured by limited resection of the bowel. Helv Paediatr Acta 33: 289-297, 1978

27. Lenzhofer R, Lindner M, Moser A, Berger J, Schuschnigg C and Thurner J: Acute jejunal ileus in intestinal lymphangiectasia. Clin Investig 71: 568-571, 1993.

28. Shima T, Ozeki M, Kinoshita T, Honda K, Inoue H and Morita S: Protein-losing enteropathy secondary to nonocclusive mesenteric ischemia: A case report. Medicine (Baltimore) 97: e13403, 2018.

This work is licensed under a Creative Commons Attribution-NonCommercial-NoDerivatives 4.0 International (CC BY-NC-ND 4.0) License. 